Proc. Indian Acad. Sci. (Earth Planet. Sci.), Vol. 105, No. 2, June 1996, pp. 143-155.

(C) Printed in India.

\title{
Three-dimensional intraplate stress distributions associated with topography and crustal density inhomogeneities beneath the Deccan Volcanic Province
}

\author{
P MANDAL and R N SINGH \\ National Geophysical Research Institute, Uppal Road, Hyderabad 500007, India \\ MS received 30 May 1994; revised 2 January 1996
}

\begin{abstract}
The generation of intraplate earthquakes has been attributed to perturbations in the stress regime, either due to surface and sub-surface loading or strength weakening of the rock mass. The present work aims at estimating the intraplate stresses associated with topography and crustal density inhomogeneities beneath the Deccan Volcanic Province (DVP). A layered crustal model with irregular interfaces of small amplitude has been used for elastostatic stress calculations. The computed principal stress differences show a significant concentration at $5-20 \mathrm{~km}$ depths beneath the western side of the region. The maximum magnitude of principal stress difierence occurs beneath the Karad at a depth of $10 \mathrm{~km}$ with a value of $60 \mathrm{MPa}$. The deviatoric stress estimates are further superposed on inferred stresses due to the regional plate tectonic forces. These results show principal stress difference concentrations beneath the Koyna, Poona and Karad regions which may thus be more vulnerable to brittle failure. It is also seen that the principal total stress directions point to the strike slip motion at Koyna, similar to that which is associated with the 1967 Koyna earthquake.
\end{abstract}

Keywork. Intraplate stresses; intraplate earthquake; Deccan Volcanic Province; topography; crustal density inhomogeneities.

\section{Introduction}

The Earth's lithosphere deforms due to both external and internal forces. These forces yield complex stress conditions which control the nature and extent of tectonic-related seismic activity within the lithosphere. Most of the global seismicity is confined to plate boundaries, and is well explained by large scale plate tectonic forces (Richardson et al 1979). Seismicity within the interior of plates requires additional processes for its explanation besides the regional plate tectonic forces. Such earthquakes have been explained by reactivation of pre-existing old faults due to local stresses (Sykes 1978; Long and Zelt 1991). Mareschal and Kuang (1986) and Kuang et al (1989) have shown that local topographic load and sub-surface mass heterogeneities may induce stresses of comparable magnitude to those induced by plate tectonic forces. They also show that these induced stresses can give rise to intraplate earthquakes.

A large number of intraplate earthquakes of magnitude $\left(m_{b}\right) 3.0-6.0$ has been observed in the Deccan Volcanic Province as shown in figures 1 and 2 (Krishna Brahmam 1975; Rao and Rao 1984). Some of the largest earthquakes in this region are: Satpura (1938), Koyna (1967) and Shimoga (1975) (Chandra 1977; Rao and Rao 1984; Talwani and Rajendran 1991; Rao 1992). The cause of this large concentration of intraplate seismicity has not yet been explained. The Koyna earthquake of 1967 which occurred in 


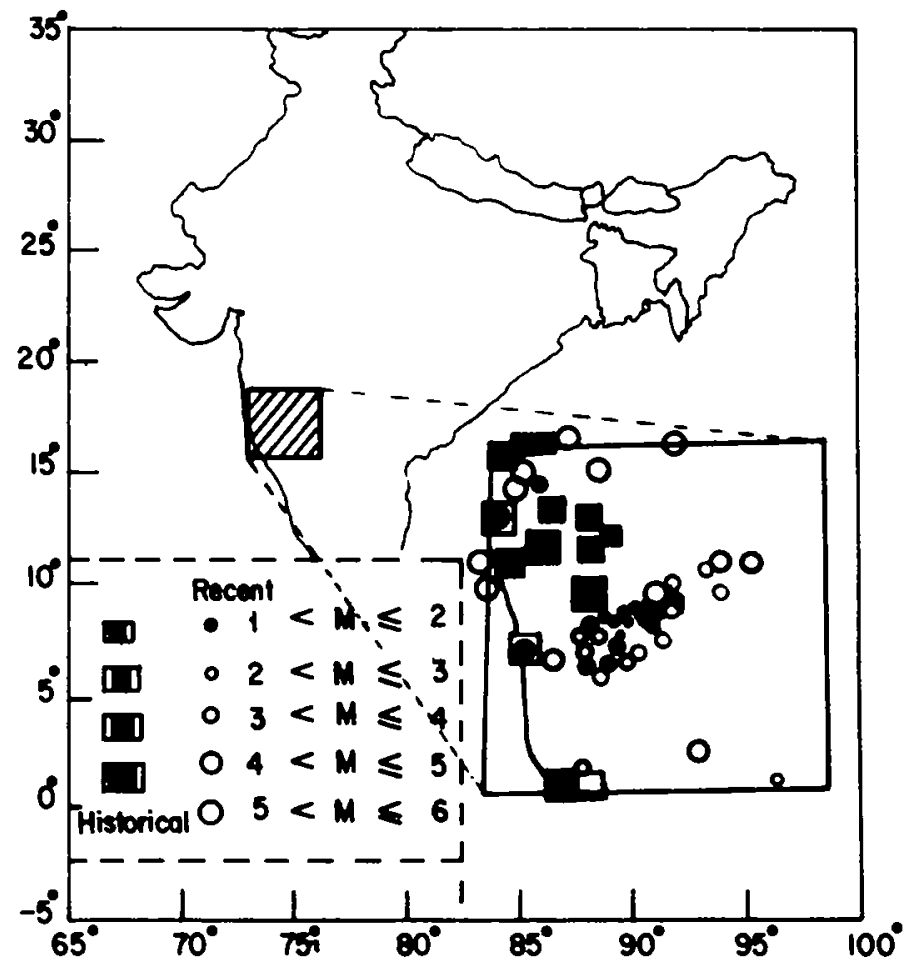

Figure 1. Historical earthquakes and recent seismicity distribution over the Decan Volcanic Province (after Rao 1992).

the western part of the Deccan Volcanic Province is the most important of these earthquakes with $m_{b} 6 \cdot 3$ (Gupta et al 1969). This earthquake has been attributed to the loading of the Koyna reservoir and associated pore pressure changes at focal depths. However, Lee and Rayleigh (1969) have pointed out that this earthquake cannot be solely caused by the vertical loading of the Koyna reservoir and have suggested that the "tectonic strains stored in the rocks in the Koyna region were the source of the energy released from the Koyna earthquake". Towards this, we estimate the local intraplate stresses due to topography and crustal density inhomogeneities in this region.

\section{Mathematical formulation}

The mathematical formulation described by Kuang et al (1989) has been used to compute the stresses due to topography and undulation of crustal interfaces. In this formulation, an $N$-layered elastic lithosphere overlies an inviscid asthenosphere (figure 3). The co-ordinate system has its origin at the surface with $z$ axis positive downward.

The elastic displacements are calculated using the following equation of equilibrium and Hooke's law:

$$
\begin{aligned}
& \nabla \cdot \sigma=-\rho \mathbf{g}, \\
& \sigma=\lambda(\nabla \cdot \mathbf{u}) I+\mu\left(\nabla \mathbf{u}+\nabla \mathbf{u}^{T}\right),
\end{aligned}
$$




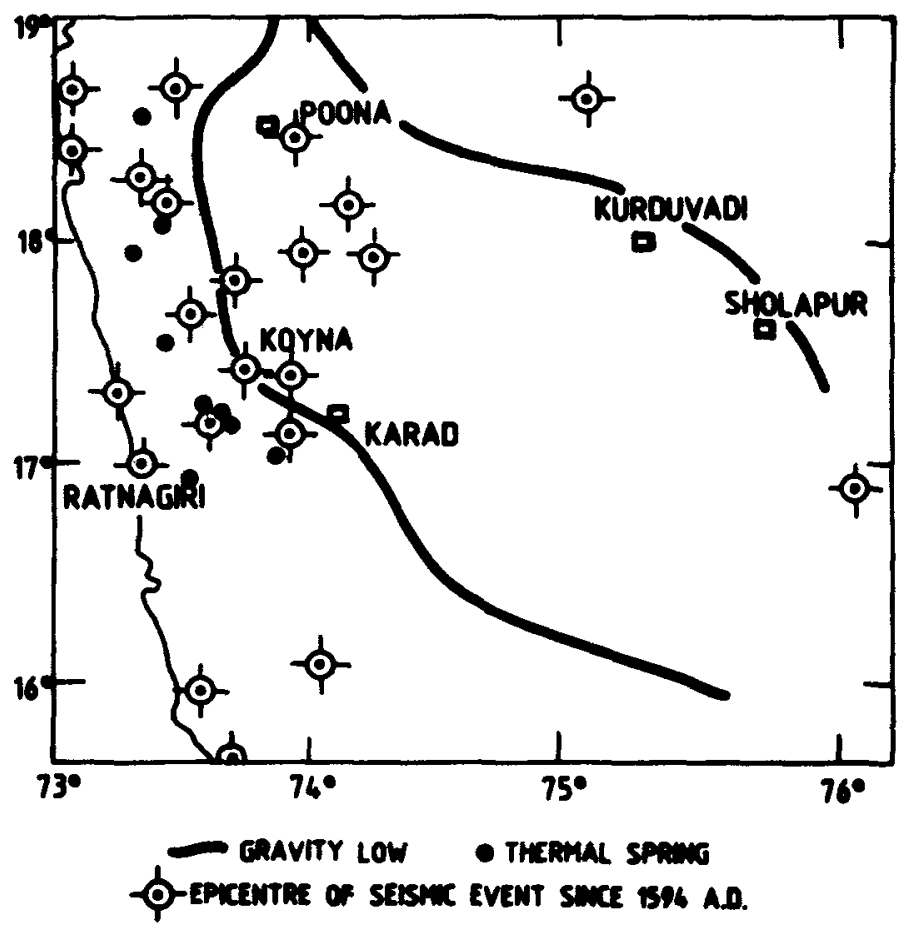

Figure 2. Map showing the relation between the gravity, geothermal springs and epicentral distributions of seismic events over the Deccan Volcanic Province (after Krishna Brahmam 1975).

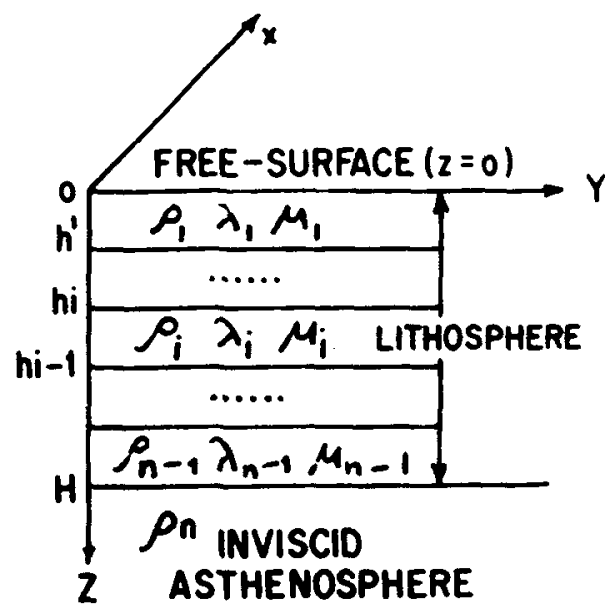

Figure 3. An N-layered elastic lithospheric slab over an inviscid asthenosphere.

where $\sigma$ is the stress tensor, $u$ is the elastic displacement vector, $\mathbf{g}$ is the acceleration of gravity, $\rho$ is the density, and $\lambda$ and $\mu$ are Lame's parameters.

The elastic displacement vector, $\mathrm{u}\left(u_{x}, u_{y}, u_{z}\right)$, satisfies the biharmonic equation

$$
\nabla^{4} \tilde{\mathbf{u}}=0 .
$$


Equation 3 is satisfied in each layer. The solution for each layer is obtained by taking the Fourier transform of the equation with respect to both horizontal co-ordinates $x$ and $y$, and solving the resulting fourth order ordinary differential equation. The general solution of the Fourier transformed displacement vector (ũ) from equation 3 (where indicates the Fourier transform) is given by (Kuang et al 1989)

$$
\tilde{\mathbf{u}}=(\mathbf{A}+\mathbf{B} \mathbf{k} z) \exp (\mathbf{k} z)+(\mathbf{C}+\mathbf{D k} z) \exp (-\mathbf{k} z),
$$

where the vectors $\mathrm{A}, \mathrm{B}, \mathrm{C}$ and $\mathrm{D}$ are arbitrary constants. $k_{x}$ and $k_{y}$ are the component of the wave vector and $\mathrm{k}=\left[k_{x}^{2}+k_{y}^{2}\right]^{1 / 2}$.

These constants ( $6 N$ for $N$ layers) are determined by using the Fourier transform of the following boundary and interface conditions which give $6 N$ conditions:

At $z=0$ (free surface)

$$
\begin{aligned}
& \sigma_{x z}^{1}=0, \\
& \sigma_{x y}^{1}=0, \\
& \sigma_{z z}^{1}-\rho_{1} g u_{z}^{1}=-\rho_{1} g h(x, y) .
\end{aligned}
$$

At $z=h^{N}$ (lithosphere-asthenosphere interface)

$$
\begin{aligned}
& \sigma_{x z}^{N}=0 \\
& \sigma_{x y}^{N}=0 \\
& \sigma_{z z}^{N}=\delta \rho^{N} g\left(\delta h^{N}(x, y)-u_{z}^{N}\right)
\end{aligned}
$$

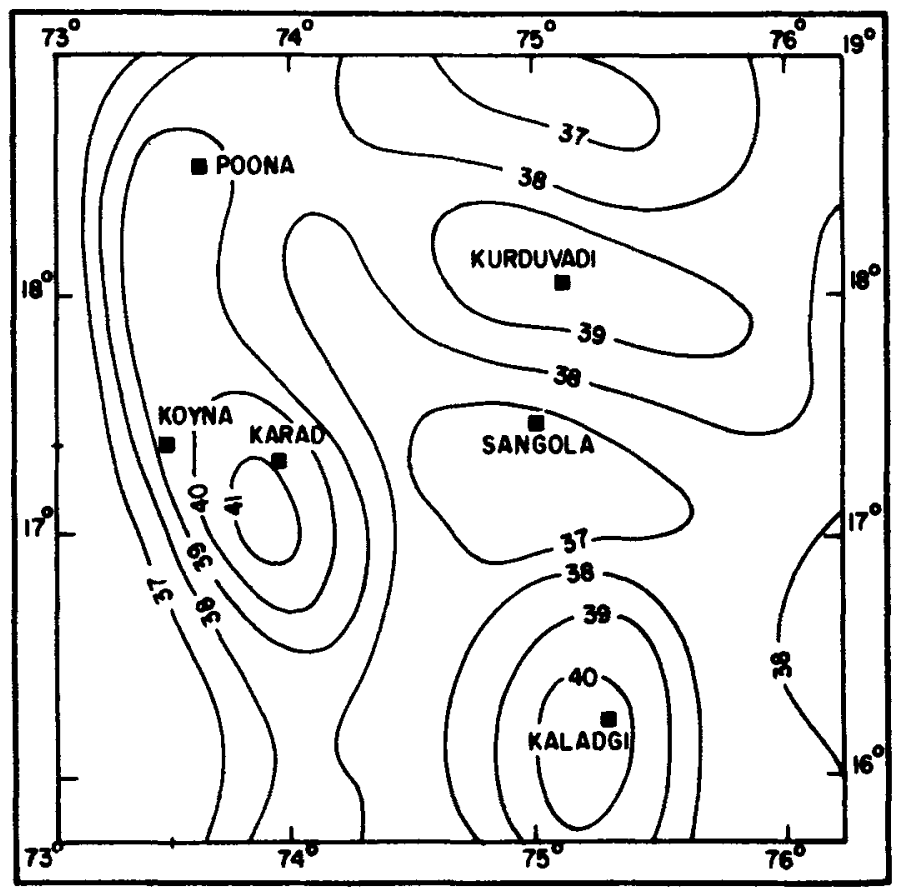

Figure 4 Moho variation in km over DVP (after Mishra 1989). 


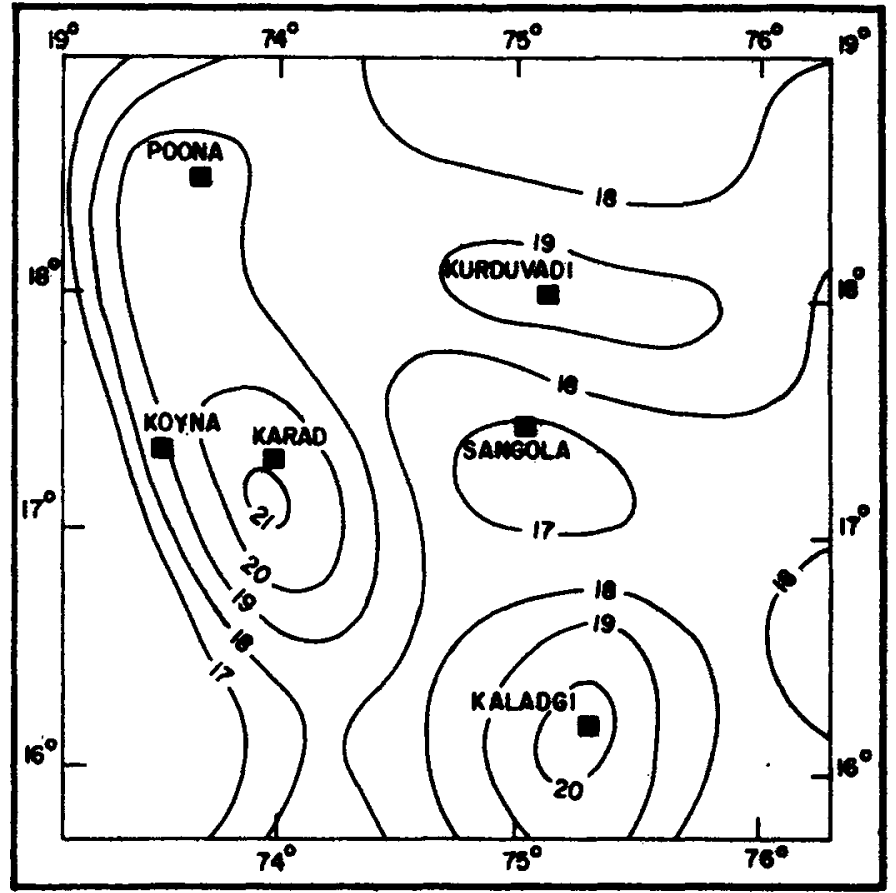

Figure 5. Conrad variation in km over DVP (after Mishra 1989).

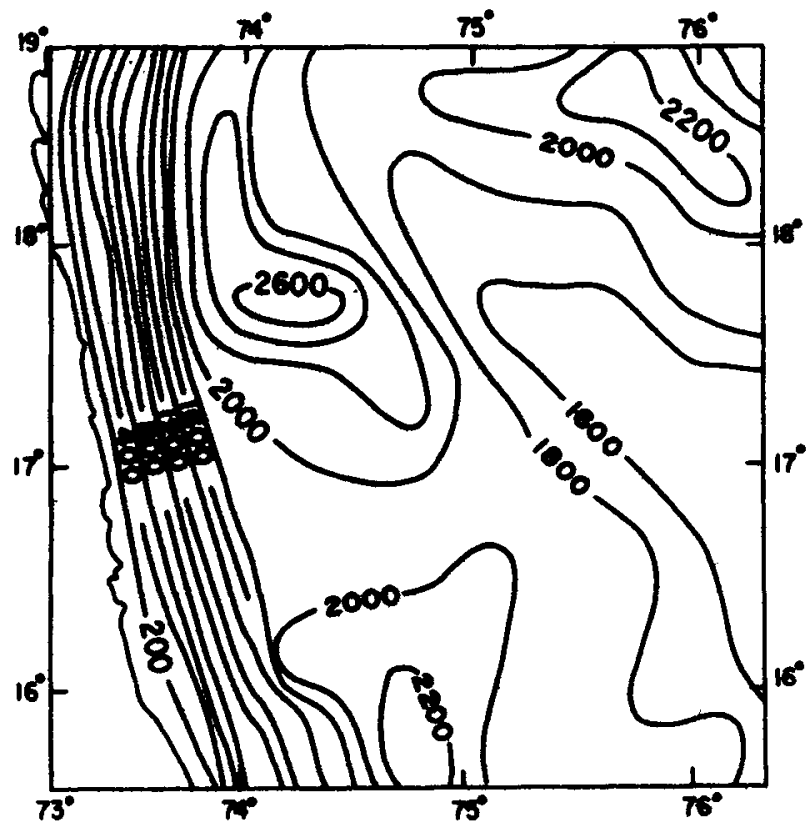

Figure 6. Topography in feet over DVP (unpublished map of Survey of India; courtesy Prof. R K Vermal. 
And at $z=h^{j}(j$ th interface $)$

$$
\begin{aligned}
& \left(u_{x}^{j}, u_{y}^{j}, u_{z}^{j}\right)=\left(u_{x}^{j+1}, u_{y}^{j+1}, u_{z}^{j+1}\right), \\
& \left(\sigma_{x z}^{j}, \sigma_{x y}^{j}, \sigma_{z z}^{j}\right)=\left(\sigma_{x z}^{j+1}, \sigma_{x y}^{j+1}, \sigma_{z z}^{j+1}+g \delta \rho^{j}\left[\delta h^{j}(x, y)-u_{z}^{j}\right]\right) .
\end{aligned}
$$

Here $\sigma_{x z}^{j}, \sigma_{x y}^{j}$ and $\sigma_{z z}^{j}$ are the stress components of the $j$ th layer; $\rho^{1}$ is the density of the 1st layer; $h(x, y)$ is the 2-D surface topography; $\delta h^{j}(x, y)$ is the undulation in the $j$ th interface and $\delta \rho^{J}$ is the density contrast across the $j$ th interface; $\delta h^{N}(x, y)$ is the undulation in the lithosphere-asthenosphere boundary; $\delta \rho^{N}$ is the density difference between the asthenosphere and the layer overlying just above it.

The solutions for displacement and stress components in the Fourier domain for each layer are obtained using these constants. The solution in the space domain is obtained by taking the inverse Fourier transform. The Fourier transformation is performed by using the Fast Fourier Transform (FFT) algorithm. A computer program based on the above mathematical formulation is developed to compute the threedimensional deviatoric stresses induced by topography and crustal density inhomogeneities. This program has been tested by reproducing the results for both analytical and crustal models as given in Kuang et al (1989). The topography and crustal thickness variations at both the Moho and Conrad are digitized at an interval of $12.1 \mathrm{~km}$ in a $(32 \times 32)$ grid. The least spectral leakage is achieved by mirroring these gridded data before taking the Fourier transform.

\section{Crustal structure beneath the Deccan Volcanic Province}

The structure below the Deccan Volcanic Province in the south Indian Shield has been extensively studied. For the analysis of a 3-D intraplate stress field due to topography and sub-surface density heterogeneities, a 3-D crustal model is used which has been obtained from gravity and Deep Seismic Sounding (DSS) studies (Kaila et al 1981a; Mishra 1989). This $375 \times 375 \mathrm{~km}$ area approximately covers a square region between longitudes $15^{\circ} 45^{\prime} \mathrm{N}$ and $19^{\circ} \mathrm{N}$ and latitudes $73^{\circ} \mathrm{E}$ and $76^{\circ} 15^{\prime} \mathrm{E}$. The crust in this region consists of two layers with density and $P$-wave velocities as $2.7 \mathrm{~g} / \mathrm{cm}^{3}$ and $6.2 \mathrm{~km} / \mathrm{s}$ respectively for the upper crust and as $2.9 \mathrm{~g} / \mathrm{cm}^{3}$ and $6.8 \mathrm{~km} / \mathrm{s}$ for the lower crust. Density values of $3.25 \mathrm{~g} / \mathrm{cm}^{3}$ and $3 \cdot 1 \mathrm{~g} / \mathrm{cm}^{3}$ have been taken for the mantle lithosphere and asthenosphere respectively. The depth of the Moho attains its maximum value of $41 \mathrm{~km}$ near Karad and decreases towards the west coast as shown in figure 4. The Conrad discontinuity also shows a similar behaviour and reaches a maximum depth of $21 \mathrm{~km}$ near Karad (figure 5). The topography shows a maximum height of 2600 feet $(\approx 792 \mathrm{~m})$ in the region just north of Karad and becomes minimum in the coastal region

\begin{tabular}{|c|c|c|c|c|}
\hline Elastic parameters & Upper crust & Lower crust & Lithospheric mantle & Asthenosphere \\
\hline P-wave velocity (m/sec) & 6200 & 6800 & 8000 & \\
\hline Poisson's ratio & $0-25$ & 025 & 0.25 & \\
\hline Lame's constant $\left(10^{11} \mathrm{~Pa}\right)$ & $0-38$ & 0.45 & 0.69 & \\
\hline Density $\left(\mathrm{kg} / \mathrm{m}^{3}\right)$ & 2700 & 2900 & 3250 & 3100 \\
\hline
\end{tabular}

Table 1. 
(figure 6). For the purpose of stress computations, a lithospheric thickness of $100 \mathrm{~km}$ is assumed for this region as also used by Watts and Cox (1989). A plate thickness of $100 \mathrm{~km}$ was also assumed by Cloetingh and Wortel (1986) for the elastic plate modelling of the Indian lithosphere. The elastic parameters used for stress computations are shown in table 1.

\section{Stress distribution beneath the Deccan Volcanic Province}

The three-dimensional stress fields associated with surface topography and internal loads have been computed at depths of $5,10,15$ and $20 \mathrm{~km}$ beneath DVP and the principal stress differences $\left(\sigma_{1}-\sigma_{3}\right)$ are shown in figures 7-10. The principal stress differences are highly variable beneath the western side of the DVP whereas the eastern side shows a more subdued pattern. The maximum stress differences occur beneath Karad with values ranging from $60 \mathrm{MPa}$ at 5 and $10 \mathrm{~km}$ depths (as shown in figures 7 and 8 respectively) to $55 \mathrm{MPa}$ at $15 \mathrm{~km}$ depth (figure 9). It decreases further to $45 \mathrm{MPa}$ at $20 \mathrm{~km}$ depth (figure 10). The maximum stress differences beneath the Karad can be explained in terms of significant downwarping of both Moho and Conrad discontinuities (figures 4 and 5 respectively). The stress differences beneath the Koyna have a maximum value of $30 \mathrm{MPa}$ at $10 \mathrm{~km}$ depth as shown in figure 8 and a value of $15 \mathrm{MPa}$ at $5 \mathrm{~km}$ depth (figure 7). For both 15 and $20 \mathrm{~km}$ depths, its value is $20 \mathrm{MPa}$ (figures 9 and 10 respectively). The stress differences beneath both Kurduvadi and Poona also show maxima at $10 \mathrm{~km}$ depth (figure 8 ).

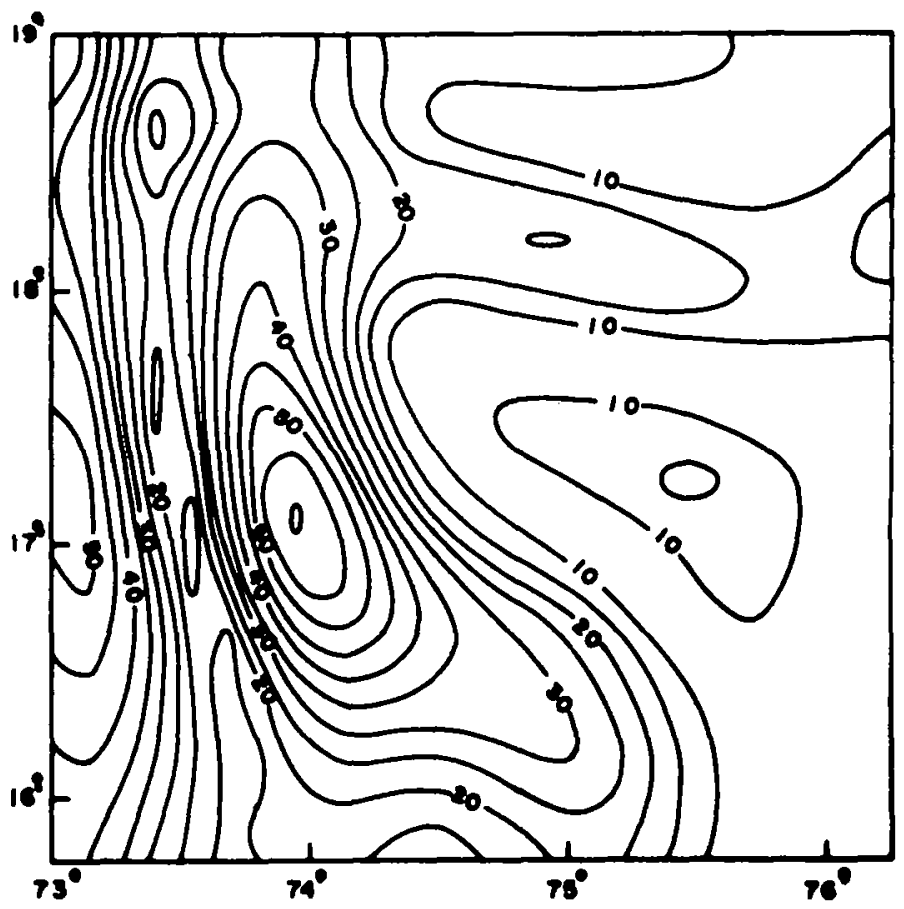

Figure 7. Local principal stress difference contours in $\mathrm{MPa}$ at $5 \mathrm{~km}$ depth. 


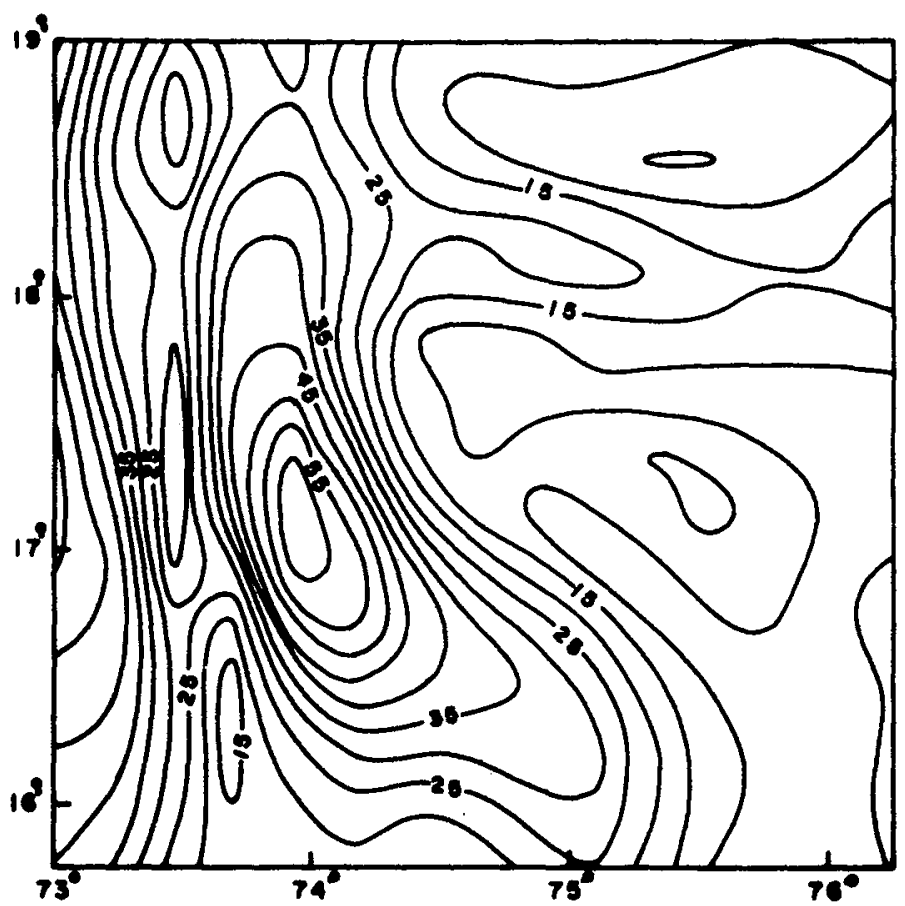

Figure 8. Local principal stress difference contours in MPa at $10 \mathrm{~km}$ depth.

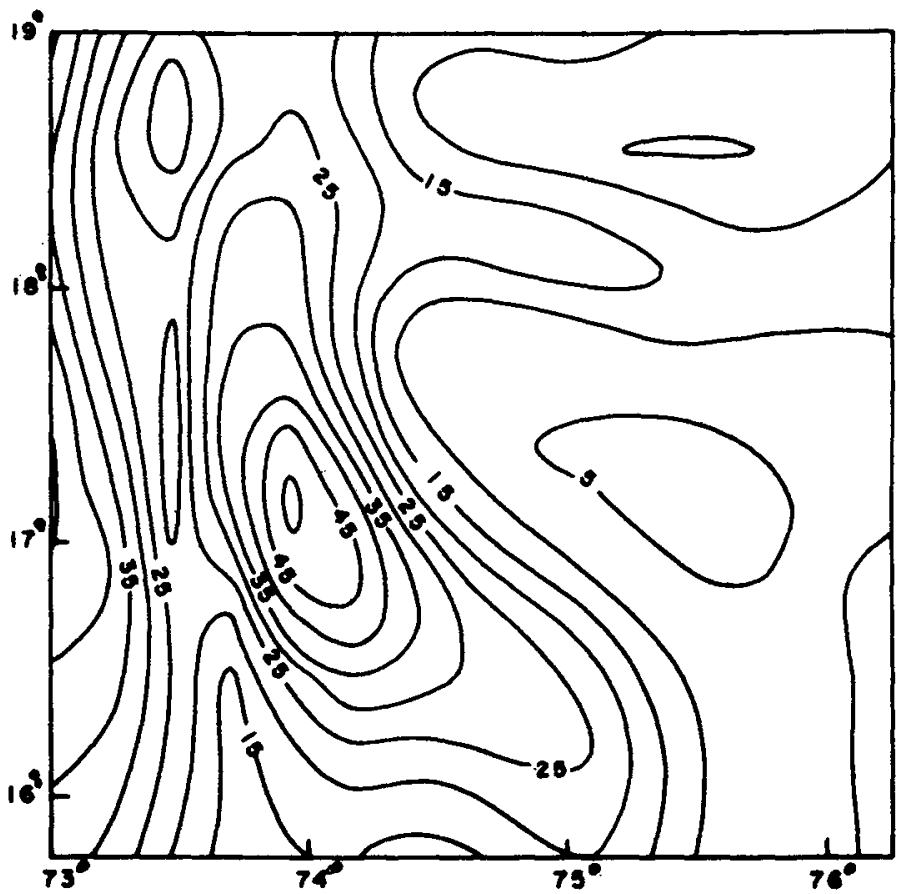

Figure 9. Local principal stress difference contours in $\mathrm{MPa}$ at $15 \mathrm{~km}$ depth. 


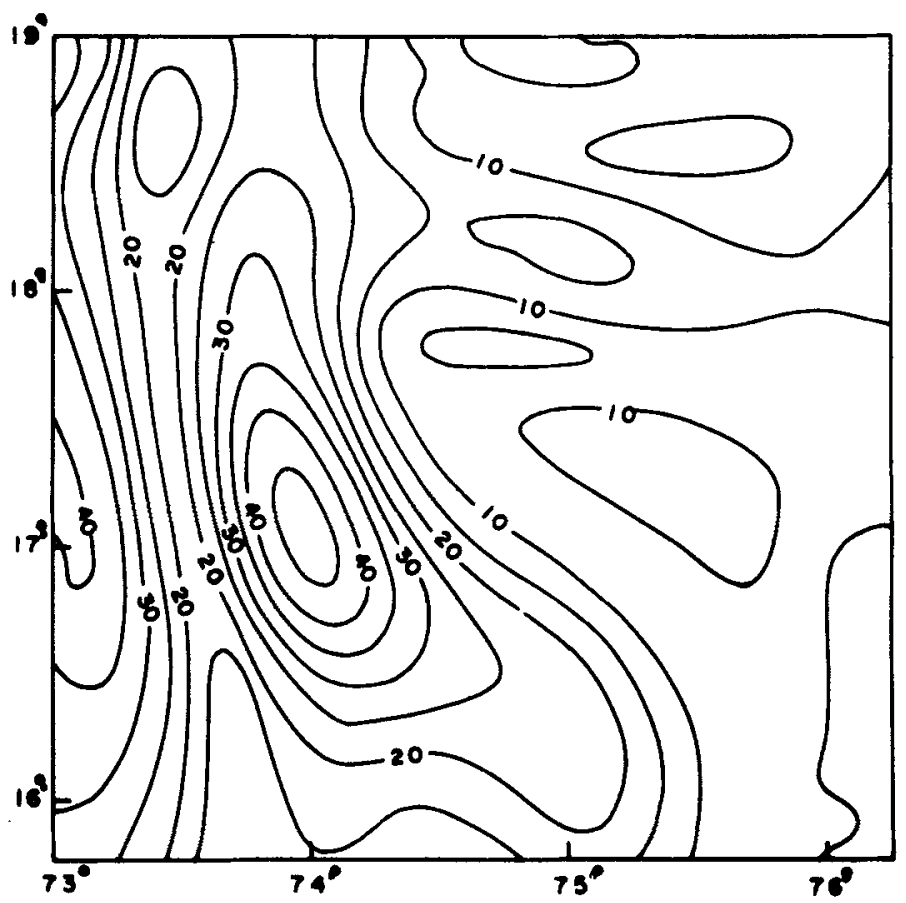

Figure 10. Local principal stress difference contours in MPa at $20 \mathrm{~km}$ depth

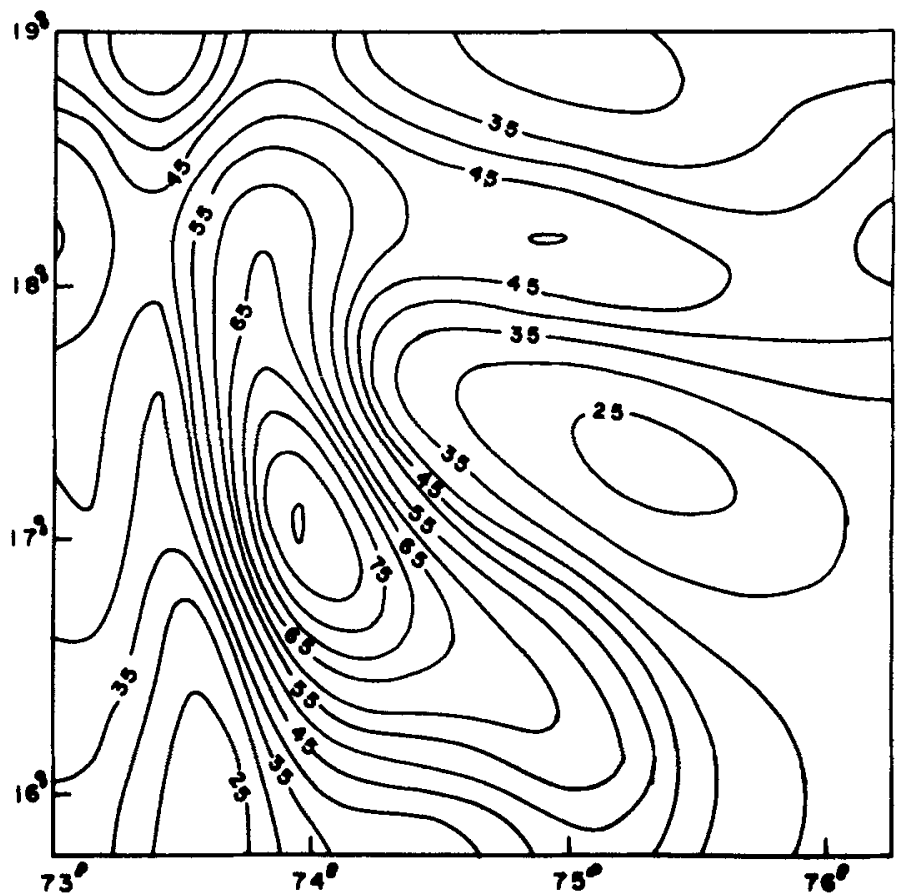

Figure 11. Resultant principal stress difference contours in $\mathrm{MPa}$ at $10 \mathrm{~km}$ depth. 
In order to obtain the total stress distribution, the effects of the plate boundary forces which induce large stresses in the Indian continental region also need to be included (Cloetingh and Wortel 1986). Thus, a regional compressive stress having a magnitude of $30 \mathrm{MPa}$ acting in the direction of $\mathrm{N} 30^{\circ} \mathrm{E}$ has been added to the local stress to infer the actual stress. The stress difference contours for the resultant stress field (figure 11) show an enhancement in their concentration beneath the western side of the region. It is observed that their maximum magnitude is $85 \mathrm{MPa}$ beneath Karad; $55 \mathrm{MPa}$ beneath Koyna; $60 \mathrm{MPa}$ beneath Poona; and $45 \mathrm{MPa}$ beneath Kurduvadi. Krishna Brahmam (1975) has delineated weak zones in the western region of the DVP using gravity, seismicity and thermal spring data (figure 2). The computed stress concentrations show good correlation with these weak zones which are involved in the shallow focus earthquake generation beneath the western side of the DVP.

These stress differences are not large enough to initiate brittle fracturing based on the usual Mohr-Coulomb failure criterion adopted for the crust. In this connection, we

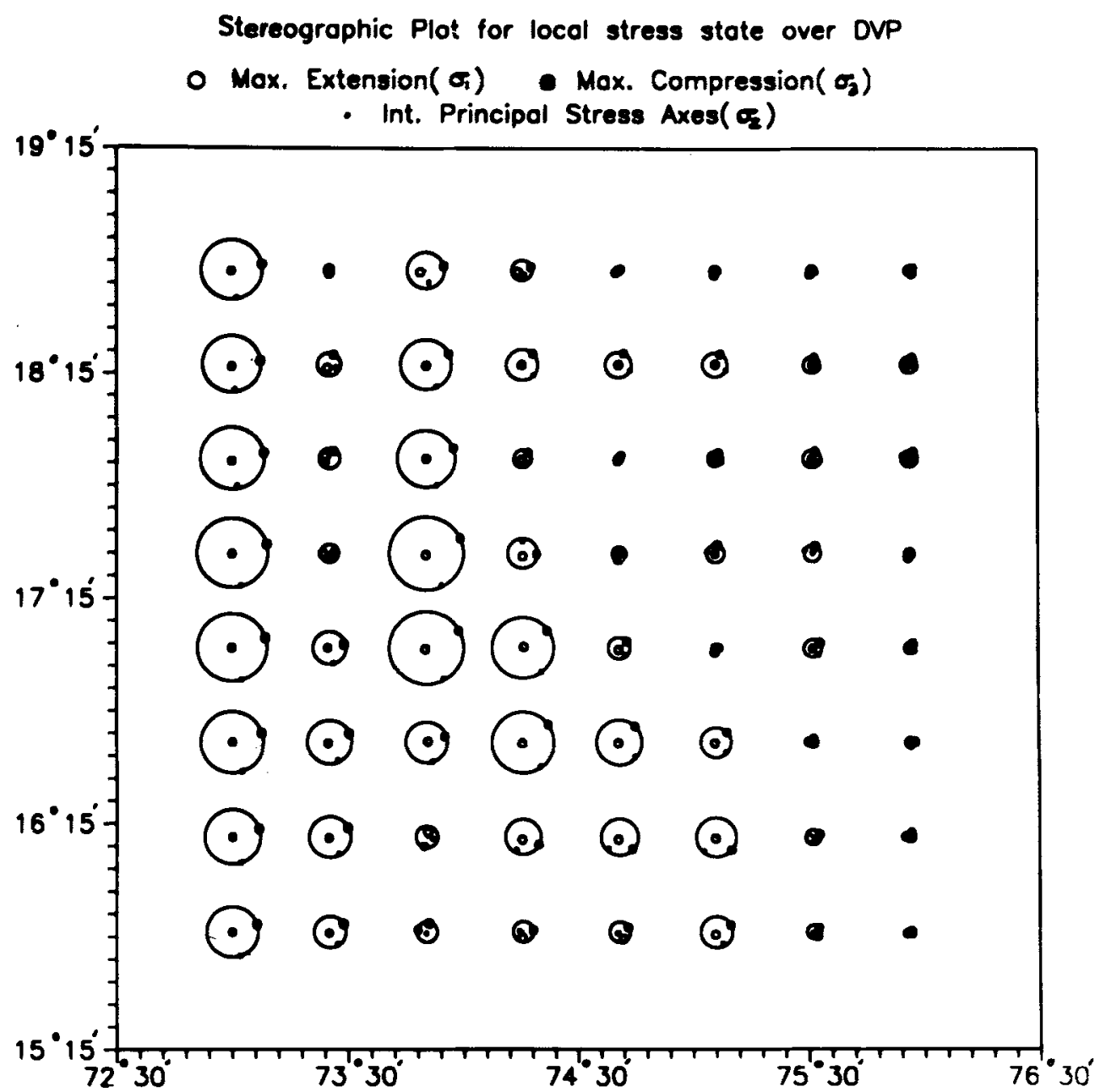

Figure 12. Stereographic plot of local principal stresses normalized to $100 \mathrm{MPa}$ at $10 \mathrm{~km}$ depth. 
note that the slip along the San Andreas fault (a plate boundary transform fault) occurs at shear stresses about five times lower than the predicted value of $150 \mathrm{MPa}$ at a depth of $15 \mathrm{~km}$ from the above failure criterion (Lachenbruch and Sass 1980; Zoback et al 1987). However, this is possible if the fault is weak and the coefficient of friction is quite small (Mount and Suppe 1987). In an interesting recent finite element modelling of fault networks of the California region, Bird and Kong (1994) suggest that the timeaveraged friction coefficient of major faults is $0 \cdot 17-0 \cdot 25$. Thus, if the fault under DVP is weak then the concentrations of the stress differences as computed would lead to brittle fracturing.

The depth of the 1967 main shock of Koyna has been reported as $10 \mathrm{~km}$ (Gupta et al 1969). Thus, the stresses at this depth are of great concern and should be analyzed in detail. The stereographic projection of these stress directions has been drawn at $10 \mathrm{~km}$ depth as shown in figure 12 . Here the size of the stress circle varies with the magnitude of $\left(\sigma_{1}-\sigma_{3}\right)$. It suggests that the regions beneath Karad, Kaladgi, Poona and

Stereographic Plot for total stress state over DVP

\section{- Max. Extension $\left(\sigma_{1}\right)$ - Max. Compression $\left(\sigma_{3}\right)$}

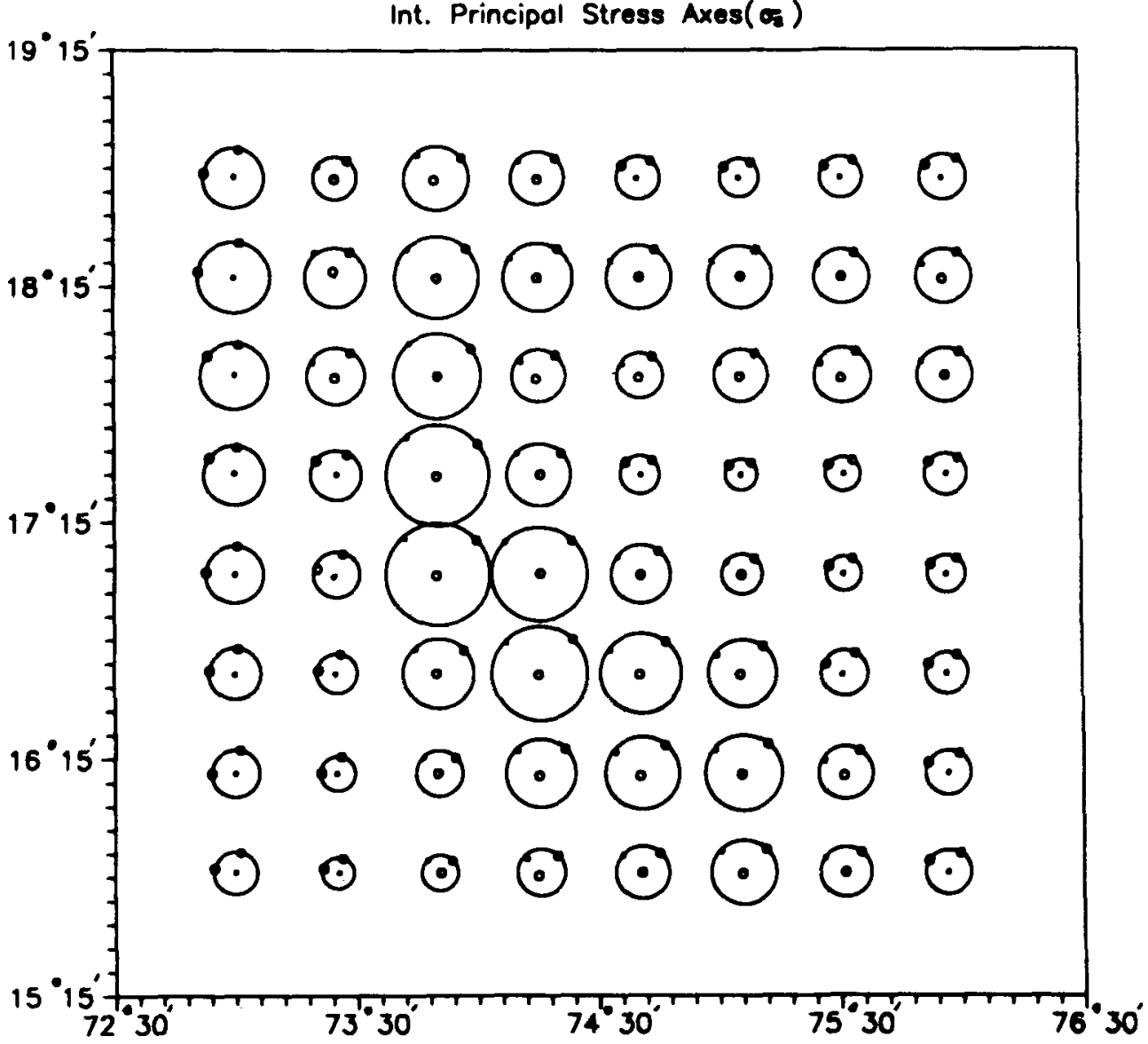

Fignre 13. Stereographic plot of resultant principal stresses normalized to $110 \mathrm{MPa}$ at $10 \mathrm{~km}$ depth. 
Kuruduvadi are characterized by northeasterly compression whereas Koyna and the coastal region in the West are dominated by NE extension. The incorporation of regional plate tectonic stresses is important in developing a comprehensive model of faulting pattern. The stereographic plot of the principal total stress directions due to both local intraplate stresses and the regional plate tectonic stresses is shown in figure 13. It is seen that the deformation mode at Koyna and the west coastal region shows strike slip whereas it suggests reverse faulting at Karad, Kaladgi, Poona and Kuruduvadi. This nature of deformation mode near Koyna agrees with the fault plane solution of the main shock of the 1967 earthquake.

\section{Conclusions}

Stress distributions due to topography and crustal density inhomogeneities have been computed with the regional stresses beneath the Deccan Volcanic Province. Based on the above computations it is concluded that:

- Local stress regime due to topography and crustal density inhomogeneities shows an extensional nature under Koyna and the west coastal regions of DVP whereas regions like Karad, Kuruduvadi and Poona are characterized by compression.

- An average trend of NW-SE for the principal stress difference contours coincides with the trend of faults and other geological features of the area (Harbinson and Bassinger 1973; Auden 1975).

- The concentration of principal stress differences in the depth range of $0-15 \mathrm{~km}$ shows good correlation with the observed seismicity of the region. These stress differences are not large enough to initiate brittle fractures based on the usual Mohr-Coulomb failure criterion. However, these are sufficient in case the faults under DVP are weak.

- The most probable region for earthquake generation would be the western side of the area where stress contours show a high magnitude as in Karad, Poona and Koyna, a result showing good agreement with the available earthquake occurrences in the area.

- Inclusion of a $30 \mathrm{MPa}$ plate tectonic force trending $\mathrm{N} 30^{\circ} \mathrm{E}$ promotes strike slip faulting beneath Koyna as observed.

\section{Acknowledgement}

The authors are thankful to Dr. H K Gupta, Director, NGRI for his encouragement and kind permission to publish this work. Thanks are due to Prof. R K Verma of Delhi University for providing us Survey of India's unpublished topographic data (200 ft contour interval) of the south Indian shield. Thanks are also due to Dr. A Manglik for useful scientific discussions.

\section{References}

Auden J B 1975 Report on the problem of seismicity associated with the Koyna reservoir, Maharashtra, India, Irrigation Department, Government of Maharashtra, Pune (India)

Bird P and Kong X 1994 Computer simulations of California tectonics; Geo. Soc. Am. Bull. 106 159-174 
Chandra U 1977 Earthquakes of peninsular India, a seismotectonic study; Bull. Seismol. Soc. Am. 67 $1387-1413$

Cloetingh S A P L and Wortel M J R 1986 Stresses in the Indo-Australian plate; Tectonophysics 132 49-67

Gupta H K, Narain H, Rastogi B K and Mohan I 1969 A study of the Koyna earthquake of December 10, 1967; Bull. Seismol. Soc. Am. 59 1149-1162

Harbinson R N and Bassinger B G 1973 Marine geophysical study of western India; J. Geophys. Res. 78 432-440

Kaila K L, Reddy P R, Dixit M M and Lazarenko M A 1981a Deep crustal structure at Koyna, Maharashtra, indicated by Deep Seismic Soundings; J. Geol. Soc. India 22 1-16

Krishna Brahmam N 1975 Geophysical studies on the Deccan traps (India); Geophys. Res. Bull. (NGRI) $2207-237$

Kuang J, Long L T and Mareschal I C 1989 Intraplate seismicity and stress in the southeastern United States; Tectonophysics 170 29-42

Lachenbruch A H and Sass J H 1980 Heat flow and energetics of the San Andreas fault zone; J. Geophys. Res. $856185-6223$

Lee W H K and Rayleigh C B 1969 Fault-plane solution of the Koyna (India) earthquake; Nature (London) 223 172-173

Long L T and Zelt K H 1991 A local weakening of the brittle-ductile transition can explain some intraplate seismic zones; Tectonophysics 186 175-192

Mareschal J C and Kuang J 1986 Intraplate stresses and seismicity: The role of topographys and density heterogeneities; Tectonophysics 132 153-162

Mishra D C 1989 On deciphering the two scales of the regional Bouguer anomaly of the Deccan trap and crust-mantle inhomogeneities; J. Geol. Soc. India 33 48-54

Mount V S and Suppe J 1987 State of stress near the San Andreas fault: Implications for wrench tectonics; Geology 15 1143-1146

Rao B R and Rao P S 1984 Historical seismicity of peninsular India; Bull. Seismol. Soc. Am. 74 2519-2533

Rao B R 1992 Seismicity and geodynamics of the low to high grade transition zone of peninsular India; Tectonophysics 201 175-185

Richardson R M, Solomon S Cand Sleep N H 1979 Tectonic stress in the plates; Rev. Geophys. Space Phys. 17 981-1019

Sykes L R 1978 Intraplate seismicity, reactivation of pre-existing zones of weakness, alkaline magmatism and other tectonism post-dating continental fragmentation; Rev. Geophys. Space Phys. 16 621-688

Talwani P and Rajendran K 1991 Some seismological and geometric features of intraplate earthquakes; Tectonophysics 186 19-41

Watts A B and Cox K G 1989 The Deccan traps: An interpretation in terms of progressive lithospheric flexure in response to a migrating load; Earth Planet. Sci. Lett. $9385-97$

Zoback M D, Mount V S, Suppe J, Eaton J P, Healy J H, Oppenheimer D, Reasenberg P, Jones L, Raleigh C B, Wong I G, Scotti O and Wentworth C 1987 New evidence on the state of stress of the San Andreas fault system; Science 238 1105-1111 